\title{
ЯЗЫКОЗНАНИЕ
}

Copyright (C) 2018 by the Kalmyk Scientific Center of the Russian Academy of Sciences

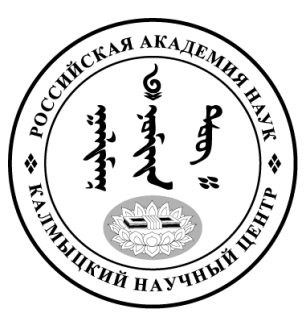

Published in the Russian Federation

Oriental Studies (Previous Name: Bulletin of the Kalmyk Institute for

Humanities of the Russian Academy of Sciences)

Has been issued as a journal since 2008

ISSN: 2619-0990; E-ISSN: 2619-1008

Vol. 40, Is. 6, pp. 86-91, 2018

DOI 10.22162/2619-0990-2018-40-6-86-91

Journal homepage: https://kigiran.elpub.ru

УДК 811.512 .3

\section{Общемонгольская лексика в названиях орудий труда в «Сокровенном сказании монголов» (параллели в халха-монгольском, бурятском, калмыцком языках)}

\author{
Анна Владимировна Мазарчук ${ }^{1}$ \\ ${ }^{1}$ младший научный сотрудник, отдел языков РФ, Институт лингвистических исследований \\ PAH (Тучков переулок, д. 9, Санкт-Петербург, Российская Федерация, 199053). ORCID: https:// \\ orcid.org/0000-0003-3679-2858.E-mail: anja_av@rambler.ru
}

\begin{abstract}
Аннотация
Введение. Слова, обозначающие орудия труда, представляют особый интерес, так как они являются неотъемлемой частью пласта бытовой лексики, а его без преувеличения можно назвать основой любого языка, на нем отражаются процессы, происходящие в языке, в том числе языковые контакты, в результате которых язык обогащается заимствованиями.

Цель. В статье рассматриваются названия орудий труда, использованные в «Сокровенном сказании монголов». Главная цель исследования состояла в том, чтобы проследить этимологию исследуемых слов и найти их параллели в халха-монгольском, бурятском и калмыцком языках, поскольку в некоторых случаях, когда этимология слова неизвестна, наличие фонетически и семантически аналогичных лексических единиц в этих основных монгольских языках, получивших статус государственных и республиканских, может рассматриваться как дополнительный аргумент, говорящий об общемонгольской природе исследуемой лексики.

Maтериалы. Язык «Сокровенного сказания монголов»- самый старый иззафиксированных в письменном виде вариантов литературного монгольского языка. Именно поэтому данный памятник был выбран в качестве источника языкового материала.

Результаты. Основываясь на таком материале, можно делать наиболее близкие к истине выводы относительно процессов сложения пласта бытовой лексики. Автор дает лексикографическое описание и приводит примеры употребления следующих терминов: büleӥ/ büleür ‘деревянная палка, мутовка для сбивания кумыса', aur ‘ступа', kituqay ‘нож’, süke ‘топор', šiüci ‘долото', šibüge ‘шило', tebene 'сапожная игла', čalir 'пешня’, gölmi qubčiur 'рыболовная сеть', gü:rege ‘кузнечный мех', uqali 'тесло', kirüe 'пила'. Подавляющее большинство этих слов относится к общемонгольской лексике. Кроме того, термины tebene 'сапожная игла' и gü:rege ‘кузнечный мех’ имеют родственные общетюркские эквиваленты.

Ключевые слова: монгольские языки, халха-монгольский язык, бурятский язык, калмыцкий язык, лексика, орудия труда, общемонгольская лексика, общетюркская лексика
\end{abstract}


«Сокровенное сказание монголов» нередко называют энциклопедией монгольского быта. Действительно, в этом литературном памятнике описано множество сцен из каждодневной жизни монголов. Благодаря этому произведению мы можем получить представление о том, чем занимались знатные и простые люди, как был устроен их быт, что они ели и пили, как сватались и женились, как вели войны и распределяли власть и многое другое.

Встречаются в тексте и названия орудий труда, которые использовали монголы: büleü/büleür - деревянные палки, мутовки, для сбивания кумыса, aur - ступы, kituqay - ножи, süke - топоры, šï̈ci - долота, šibüge - шилья, tebene - сапожные иглы, čalir - пешни, gölmi qubčiur - рыболовные сети, gü:rege - кузнечные меха, uqali - тесла, kirüe - пилы. Как таковые технологические процессы, в которых использовались бы эти предметы, в «Сокровенном сказании» практически не описываются. Перечисленные орудия труда чаще всего упоминаются между прочим. Некоторые из них герои летописи используют как оружие. Некоторые названия орудий труда употребляются в составе метафор. Приведем примеры употребления исследуемых терминов в тексте ${ }^{1}$ :

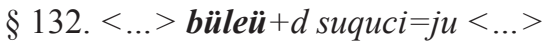

'< .. > вытащили колотушки $<\ldots$..>'

$\S 85 .<\ldots>$ büleür - ün dawu sonos $=$ cui $<\ldots>$

'< ...> услышал звук колотушек $<\ldots$..

$\S 152$. Erde üdür ke:=esü doloan nasu-tu-yiMerki+d irgen dawuli=ju od $=c u$ qara alaq ešigedaqu emüs $=g e=j u ̈$ Selenge-yin Buura_keer-e Merki $+d$ ünaurnödü=be @ @gü.

'В семилетнем возрасте его угнали в плен Меркиты, и там он, в кожухе из черно-рябого козленка, в Селенгинской пустыне Буури-кеере толок ведь просо в Меркитских ступах'.

§ 178. šigi quruun-u-an toli onubci kituqay-bar $q a d q u=j u$

'уколол свой палец зеркальным ножичком для сверления стрел'.

$\S 80$. tere amasar bögle $=n$ una $=q$ san qošiliq-un tedüy caqa:n gürü horci=n qar=basu ülü bol=qu modu $+d-i$ sumuci kituqay-bar-iyan hoqtori $=a d$

1 Транслитерация приводится по [Street 2013]. Перевод дается в основном по [Козин 1941], с опорой на [Палладий 1866], [Cleaves 1982], [Rachewiltz 1972], [Дамдинсүрэн 1957]. mori-yan qaltari=ul=uad qar=quy-lua Tayiciu $+d$ saki=ju $a=j u u$.

'И принялся срезать своим ножом для очинки стрел, срезать деревья, которые не давали прохода, окружая тот белый валун, величиной с юрту, что свалился откуда-то и заслонил проход. Кое-как провел он свою спотыкавшуюся лошадь и уже стал было выходить на прогалину, а тайчиуды [тут как тут,] сторожат'.

$\S$ 149. Kö̈̈+d deü+ner-i in-u güyice $=$ jü ire $=k \ddot{u} y$ lüe Širgüetü ebügen bos $=u n \sim$ yada $=q u$ Tarqutay- $i$ tergen deere $u n u=j u$ gedergü deere in- $u$ aqtala $=n$ sau=ju kituqay qar=qa=ju. $<\ldots>$ yeke $\sim$ kituqayiyar-a:n qoolay in-u ququl=ura gür=küy-tür Tarqutay_kiriltuq yeke dawu-ar deü+ner kö̈̈+diyen qayla $=j u<\ldots>$

'Когда подбежали его (Таргутая) сыновья и младшие братья, Ширгуету-эбугенсел на спину Таргутаю, который упал на телегу и не мог встать, и вытащил нож <..> Когда уже был готов полоснуть своим большим ножом по горлу, Таргутай громким голосом закричал своим младшим братьям и сыновьям: < .. >'

$\S$ 154. Gü̈̈n tutum qancun-dur-iyan kituqay qancula $=j u$ dere $a b=$ un $\ddot{u} k \ddot{u}=y e$

'Умрем, спрятав каждый в своем рукаве нож'.

$\S 214$. < .. > kituqay-ban temtel $=j \ddot{u}<\ldots>$ kituqay juqul=un bü=küy qar in-u bari=ju tata=quy-lua kituqay-ban alda=juuy $<\ldots>$ Jetey Jelme qoyar süke bari=ju <...> Tatar-un Qargil_ šira-yi süke-ber kituqay-bar mün tende ala=juuy <...> Nama-yi güyi=jü güyice=jü šibilger in-u bari=ju kituqay juqul=uqsan qar in-u tata=ju kituqay ese alda=qsan $b \ddot{o}=e$ es Jetey Jelme qoyar-i gür=cü ire=tele kö̈n-ü amin-tur qor ülü@ü: gür=ge=gü bü=lee

'< ..> нащупывал свой нож < ..> рванула за руку, которая заносила нож, и [он] свой нож потерял <.. > Татарского Харгил-Ширая точно бы там убили своими топорами и ножами. <..> Чжетай и Чжельме схватили топоры <.. > Если бы я не догнала его, не вцепилась ему в косу и не рванула за руку, занесшую нож, то он не потерял бы ножи успел бы погубить ребенка раньше, чем подоспели бы Чжетай с Чжельме'.

$\S$ 195. Qaraqana yorcil yorci=ju naur $\sim$ bayi-du bayi=ldu=ju šiüci qadquldua qadqu=ldu=ya

'Пройдем через карагану, будем сражаться [даже] в том месте, где озеро, будем биться [даже] долотами'.

$\S$ 195. šiüci qošiu-ta $+n$ šibüge kele-te $+n$

'С мордами-долотами, с языками-шилами'.

$\S 195$. šibüge-de qadqu=quy-a cölö $\sim \ddot{u} g e \ddot{u}$ 
'Не проколется [и] шилом' .

$\S 195$. tebene-de qadqu=quy-a cölö ügeü 'Не проколется [и] большой иглой'.

$\S$ 199. Tarbaqan bol=ju kimusu-ar-iyan malta $=j u$ qajar-tur oro=asu calir bol=ju coki=ju eri=jü ülü@ü: güyice=gü ci.

'[Если] обернутся тарбаганами и зароются когтями в землю, исполни [приказ]: стань пешней и ударь [ею по земле], найди их'.

$\S$ 199. Jiqasun bol=ju Te $e^{n}$ is dalay-tur oro $=$ asuci Sübeetey gölmiqubciur bol=ju šiü=jü qubci=ju ülü@ü: $a b=q u c i$.

'[Если] обернутся рыбой и уйдут в море, ты, Субедей, исполни [приказ]: стань неводом-сетью и поймай их'.

$\S$ 199. Jarciu^day ebügengü:rege-ben $\ddot{u}: r=c \ddot{u}$.

'Старик Джарчиудай, неся на плечах свой кузнечный мех’.

§ 240. süke uqali kirüe šiüci ere-yin jer jebseg jasa $=u l=j u$ hulaan $\sim$ buqa-yin yabu=qsan mör-iyer mör-tür bayi=qsan modu $+d$ hoqtocin $c a b c i=u l=j u$ kirügede $=\ddot{u} l=j u ̈$ mör $b o l=q a=j u$.

'Вооружив ратников топорами, тесаками, пилами и долотами и всяким потребным инструментом, он приказал прорубать просеку по следу буйволов, пилить и рубить деревья'.

Почти все названия орудий труда, употребленные составителем «Сокровенного сказания», можно классифицировать как общемонгольские лексические единицы. Некоторые из них родственны соответствующим тюркским терминам. Рассмотрим каждое слово по отдельности ${ }^{1}$.

1. büleü/büleür соответствует письм. монг. büligür/bülegür 'мутовка, колотовка'. Название орудия труда образовано от глагольного корня büli-/büle- 'взбалтывать, мешать, взбивать' с помощью аффикса -gür, образующего имена со значением «орудие труда» [Бобровников 1849: 61]. В «Калмыцком словаре» Г. Й. Рамстедта различаются глаголы bülikü 'мешать, сбивать масло' vs. bülekü 'колоть, жалить' и соответственно büligür 'палка, которой сбивают кумыс в мешке' vs. bülegür 'жало' [Ramstedt 1935: 66b, 67a]. В современных халха-монгольском, калмыцком и бурятском языках (кроме западного наречия бурятского) значения

\footnotetext{
${ }^{1}$ В качестве основных словарей использовались [Ковалевский 1844; 1846; 1849] для письменного монгольского, [БАМРС] — для халхамонгольского, [Черемисов 1951] - для бурятского, [КРС 1977] — для калмыцкого языка.
}

слова, восходящего к письм. монг. büligür, и соответствующего глагола не изменились: халх. бүлүүр 'мутовка, пахтальная мутовка, мешалка (для взбивания кобыльего молока при приготовлении кумыса или масла)' $<$ халх. бүлэх 'мешать, болтать, пахтать, взбалтывать, сбивать, сепарировать (напр., кумыс, масло)'; калм. бүлүр 'мутовка, мешалка (для пахтанья масла)', бүлх 'сбивать масло’; бур. бүлүYр '1. деревянная мешалка (для пахтанья масла) < бүлэхэ 'сбивать (масло, курунгу)'. В западном наречии бурятского языка слово бүлүүр означает 'узкая и высокая кадушка (для пахтанья масла)'

2. aur соответствует письм. монг. aүuи ‘ступа' [Голстунский 1895: 12b]. Те же значения перешли и в современные языки: халх. уур 'ступка, толчея, ступа, отверстие в ступе (куда кладут зерно)', бур. уур 'ступка (для толчения)', калм. yp 'ступка (для толчения)'. Строго говоря, ступа сама по себе, без пестика (письм. монг. nüdügür), не является орудием труда, но пест в «Сокровенном сказании монголов» не упоминается.

3. Также не во всех случаях орудием труда можно назвать нож. В тексте «Сокровенного сказания» он чаще выступает как оружие (примеры из $\S ~ 149,154,214)$. Но режуще-колющие свойства ножа использовались и в быту. Нож как орудие труда упоминается в $\S 178$ и 80 , хотя и там это особые виды ножей для очинки стрел - то есть, для создания и обработки оружия (toli onubci kituqay 'зеркальный ножик для нанесения зарубок (ушков) на конец стрелы' и sumuci kituqay 'нож для отделки стрел').

Слово с общим значением «нож» -

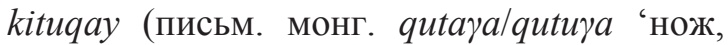
ножик') - общемонгольское, восходит к праформе *kïtuga(ï) 'нож' [Nugteren 2011: 414]. Сохранилось в современных языках: халх. хутга(н) 'нож, ножик', бур. хутага 'нож, ножик', калм. $y m x$ 'нож, ножик'.

Термин опubci (письм. монг. оnobči 'инструмент (ножичек), которым делают ушки у стрелы') образовался в результате присоединения аффикса $-b c ̌ i$ к существительному письм. монг. oni 'ушко, зарубка у стрелы' (<*onï/*ona (?*honi) 'зарубка на стреле' [Nugteren 2011: 468]). В словаре [Ковалевский 1844: 341b] зафиксирована только форма oni, но в словарях современных халха-монгольского и бурятского языков указаны две формы: халх. онь 'ушко, зарубка на конце стрелы (которой она накладывается на тетиву)'/ он 'насечка, зарубка (на кон- 
це стрелы)', бур. они 'зарубка у стрелы (для накладывания на тетиву)'/ оно(н) 'зарубки (на стреле), развилинки’. Для калмыцкого языка указана одна форма - калм. он 'насечка, зарубка (на конце стрелы)'. Производное от них название ножа, соответствующее письм. монг. onobči, сохранилось в халха-монгольском и калмыцком языках: халх. оновч 'ножик (для нанесения зарубок, ушков на конец стрелы), ножичек, небольшой нож (употребляющийся при изготовлении стрел, для прорезывания ушков)', калм. оновч 'нож (для нанесения насечек, зарубок на конец стрелы)'.

Название ножа sumuci происходит от письм. монг. sumun 'стрела' (халх. сум(ан), бур. hомо(н), калм. сумн 'стрела') <*sumun 'стрела'. [Nugteren 2011: 505]. Из современных языков до сих пор бытует в халха-монгольском и бурятском языках: халх. сумч (хутга) 'острый, небольшой нож для отделки стрел', бур. һомошо (хутага) 'небольшой портативный нож'.

4. Термин šiüci (письм. монг. с̌йče 'долото') восходит к праформе *siüč ' 'долото' [Nugteren 2011: 498]. Параллели в современных языках: халх. иүYи 'долото, стамеска', бур. Һүүшэ 'долото', калм. шүүнч 'долото, стамеска'.

5. Обозначение шила šibüge (письм. монг. šibüge“шило') восходит к праформе *sibege [Nugteren 2011: 494]. Современные формы: халх. шөвөг 'шило, дырокол, зонд', бур. шүбгэ 'шило’ (зап. бур. 'вилка'), калм. шөвг 'шило’ ([Ramstedt 1935: 362a, 367a]: šiwg , šöwg $\left.{ }^{\ddot{ }}, \check{s} \ddot{o} w g \partial\right)$.

6. Слово tebene (письм. монг. tebene 'большая игла') восходит к праформе *tebene/*temene 'большая игла', родственной тюрк. *temen id. [Nugteren 2011: 515; ДТС 1969: 551a]. Современные формы: халх. тэвнэ 'большая и толстая игла', бур. тэбэнэ 'большая игла', калм. темн '1. большая игла; 2. металлический наконечник (для протыкания перегородки ноздрей верблюда)'.

7. Термин calir (письм. монг. čalir/čaril 'пешня, кирка, железный лом') восходит к праформе * čalir čaril 'лом' [Nugteren 2011: 258]. Слово осталось в халха-монгольском и бурятском языках: халх. цุалир/ царил 'лом, пешня, кирка, мотыга', бур. салир 'пешня, лом (для пробивания льда)'. В словаре современного калмыцкого языка это слово не зафиксировано, есть только русское заимствование: калм. пешнә 'лом'. Калмыцкое соответствие слову письм. монг. čalir мы находим только в словаре Г. Й. Рамстедта: tšalr $/$ šälr 'железный кол с острием, пешня' [Ramstedt 1935: 421a].

8. В тексте «Сокровенного сказания» использованы в качестве парного слова два термина, каждый из которых обозначает невод, или бредень - gölmi qubciur. Первое слово в письм. монг. языке имеет два варианта написания: gölmi и gölm-e ('большая рыболовная сеть, невод’). Формы в современных языках: халх. гөлмий 'невод', бур. гүльмэ 'рыболовная сеть', калм. гөлм 'рыболовная сеть, невод’. Второе слово тоже может быть записано двумя способами: письм.

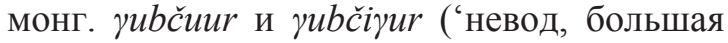
рыболовная сеть’). Оно до сих пор имеет хождение в халха-монгольском и бурятском языках, как и глагольный корень, от которого слово образовалось с помощью аффикса -үur: халх. говчуур 'большая рыболовная сеть, большой невод, бредень (небольшой невод), тента, трал, ловушка' < говчих 'ловить рыбу сетью, неводом, тралить, неводить'; бур. губшуур 'невод, рыболовная сеть' < губшаха 'ловить неводом'.

9. Термин gü:rege (письм. монг. kegürgel kügürge 'раздувальный мех') восходит к праформе *köerge (?*kü̈̈rge) 'кузнечные мехи', родственной тюрк. *kö:rk id. [Nugteren 2011: 423-424; ДТС 1969: 318b]. Современные параллели: халх. хөөрөг 'кузнечный мех, раздувальные меха', бур. хөөргэ 'кузнечный мех', калм. көөрг 'кузнечные мехи'.

10. Слово süke (письм. монг. süke 'топор, секира') восходит к праформе * süke 'топор' [Nugteren 2011: 508]. Современные паралле-

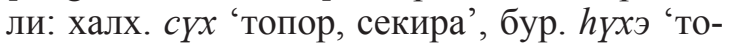
пор', калм. сүк 'топор'.

11. Термин uqali (письм. монг. ojoli 'топорик с поперечным острием, тесло, пазник') восходит к праформе *oali 'тесло' [Nugteren 2011: 465]. Современные параллели: халх. ооль (оолин) 'тесло', бур. ооли 'долото, тесло', калм. ооль 'тесло’.

12. Слово kirüe (письм. монг. kirüge 'пила') восходит к праформе *kirüe> *kiröe 'пила' [Nugteren 2011: 416]. Современные параллели: халх. хөрөө(н) 'пила', бур. хюрөө 'пила', калм. көрә 'пила'.

Таким образом, в «Сокровенном сказании монголов» мы насчитали 14 лексических единиц, которые можно отнести к семантической группе «орудия труда» - некоторые из них с оговорками (aur 'ступа' и kituqay 'нож’). Два слова - tebene 'большая игла' и gü:rege 'кузнечные меха' - имеют родственные тюркские корреляты. 


\section{Сведения о финансировании}

Исследование выполнено при финансовой поддержке РФФИ в рамках научного проекта № 16-24-03001-ОГОН.

\section{ЛИТЕРАТУРA / REFERENCES}

БАМРС - Большой академический монгольскорусский словарь в 4-х томах / отв. ред. Г. Ц. Пюрбеев. Т. 1. М.: Academia, 2001. 520 с. [Bol'shoi akademicheskii mongol'sko-russkii slovar' [Unabridged Academic MongolianRussian Dictionary]. Vol. 1-4. Ed. by G. Ts. Pyurbeev. Vol. 1. Moscow: Academia, 2001. 520 p. (In Rus. and Kalm.)]

Бобровников 1849 - Бобровников A. A. Грамматика монгольско-калмыцкого языка. Казань: Университет. тип., 1849. 403 с. [Bobrovnikov A. A. Grammatika mongol'skokalmytskogo yazyka [A Grammar of the Kalmyk Mongolian language]. Kazan: Kazan Imperial Univ., 1849. 403 p. (In Rus.)]

Голстунский 1895 - Голстунский $К . \Phi$. Монгольско-русский словарь, составленный профессором С.-Петербургского университета К. Ф. Голстунским. Том первый. С.Петербург, 1895. 491 с. [Golstunsky K. F. Mongol'sko-russkii slovar', sostavlennyi professorom S.-Peterburgskogo universiteta K. F. Golstunskim [Mongolian-Russian dictionary compiled by prof. of St. Petersburg University K. F. Golstunsky]. Vol. 1. St. Petersburg, 1895. 491 p. (In Rus.)]

Дамдинсүрэн 1957 - Монголын нууц товчоо. Улаанбаатар: Улсын хэвлэлийн газар, 1957. 251 c. [Mongolyn nuuts tovchoo [The Secret History of the Mongols]. Ulaanbaatar: National Publ. House, 1957. 251 p. (In Mong.)]

ДТС 1969 - Древнетюркский словарь. Л.: Наука, 1969. 677 с. [Drevnetyurkskii slovar' [Old Turkic dictionary]. Leningrad: Nauka, 1969.677 p. (In Rus.)]

Ковалевский 1844 - Ковалевский О. Монгольско-русско-французский словарь. Т. І. Казань: Университетская типография, 1844. 594 c. [Kowalewski J. E. Mongol'sko-russko-frantsuzskii slovar' [Mongolian-RussianFrench dictionary]. Vol. 1. Kazan: Kazan Imperial Univ., 1844. 594 p. (In Rus., Mong. and Fr.)]

Ковалевский 1846 - Ковалевский О. Монгольско-русско-французский словарь. Т. ІІ. Казань: Университетская типография, 1846. 951 c. [Kowalewski J. E. Mongol'sko-russko-frantsuzskii slovar' [Mongolian-RussianFrench dictionary]. Vol. 2. Kazan: Kazan Imperial Univ., 1846. 951 p. (In Rus., Mong. and Fr.)]
Ковалевский 1849 - Ковалевский О. Монгольско-русско-французский словарь. Т. III. Казань: Университетская типография, 1849. 1144 c. [Kowalewski J. E. Mongol'sko-russkofrantsuzskii slovar' [Mongolian-Russian-French dictionary]. Vol. 3. Kazan: Kazan Imperial Univ., 1849. 1144 p. (In Rus., Mong. and Fr.)]

Козин $1941-$ Козин C. A. Сокровенное сказание. М., Л.: Изд-во Академии наук CCCP, 1941. 619 c. [Kozin S. A. Sokrovennoe skazanie [The Secret History of the Mongols]. Moscow, Leningrad: USSR Acad. of Sc., 1941. 619 p. (In Rus.)]

КРС 1977 - Калмыцко-русский словарь / под ред. Б. Д. Муниева. М.: Русский язык, 1977. 768 c. [Kalmytsko-russkii slovar' [KalmykRussian dictionary]. B. D. Muniev (ed.). Moscow: Russkiy Yazyk, 1977. 768 p. (In Rus.)]

Палладий 1866 - Старинное Монгольское сказание о Чингисхане // Труды членов Российской духовной миссии в Пекине. Том IV. СПб.: Типография В. Безобразова и Комп., 1866. С. 3-258. [An ancient Mongolian tale of Genghis Khan. Trudy chlenov Rossiyskoy duhovnoy missii v Pekine [Works by members of the Russian Orthodox Mission to Beijing]. Vol. 4. St. Petersburg: V. Bezobrazov an $\mathrm{C}^{\circ}$, 1866. Pp. 3-258. (In Rus.)]

Черемисов 1951 - Бурят-монгольско-русский словарь / сост. К. М. Черемисов, под ред. Ц. Б. Цыдендамбаева. М.: Гос. изд-во иностранных и национальных словарей, 1951.852 c. [Buryat-mongol'sko-russkiislovar' [Buryat-Mongolian-Russian dictionary]. K. M. Cheremisov (comp.), Ts. B. Tsydendambayev (ed.). Moscow: State Publishing House of Foreign and National Dictionaries, 1951. 852 p. (In Rus. and Bur.)]

Cleaves $1982-$ Cleaves $F$. $W$. The Secret History of the Mongols. Vol. I. Harvard University Press, Cambridge, Massachusetts, London, England, 1982. 277 p. (In Eng.)

Nugteren 2011 - Nugteren H. Mongolic Phonology and the Qinghai-Gansu Languages. Utrecht, 2011. 563 p. (In Eng.)

Rachewiltz 1972 - Rachewiltz I. Index to the Secret History of the Mongols. Bloomington: Indiana University, 1972. 347 p. (In Eng.)

Ramstedt 1935 - Ramstedt G. J. Kamükisches Wörterbuch [A dictionary of Kalmyk]. Helsinki: Finno-Ugric Society, 1935. 560 p. (In Germ. and Kalm.)

Street 2013 - Street J. C. Street's Text Of The Secret History Of The Mongols. Version 24 of 10 October 2013. Available at: http://altaica.ru/ SECRET/e_street.php (In Eng.) 
UDC 811.512 .3

\section{Common Mongolian Lexis Denoting Tools of Trade in The Secret History of the Mongols (Parallels in the Khalkha- Mongolian, Buryat and Kalmyk Languages)}

Anna V. Mazarchuk ${ }^{1}$

${ }^{1}$ Junior Research Associate, Department of Languages of Russia, Institute for Linguistic Studies of the RAS (9, Tuchkov Bystr., St. Petersburg, 199053, Russian Federation). ORCID: https://orcid. org/0000-0003-3679-2858. E-mail: anja_av@rambler.ru

\section{Abstract}

Introduction. The words denoting tools of trade are of particular interest since those are integral to the lexical layer which can be defined as 'household vocabulary', while, it would be no exaggeration to say, this lexical layer forms the basis of any language and reflects the processes occurring in the language, particularly the facts of contacts with other cultures that would have resulted in linguistic borrowings.

Goals. The article deals with the vocabulary denoting tools of trade in The Secret History of the Mongols. The study primarily aims to track the etymology of the words in question and discover their parallels in the modern Khalkha, Buryat and Kalmyk languages, since, in some cases, when the etymology is unclear, the fact of presence of phonetically and semantically identical lexical units in the mentioned major Mongolic languages to have acquired official state and republican status may be regarded as an additional evidence of the common Mongolic origin of the vocabulary under study.

Materials. The language of The Secret History of the Mongols is the oldest physically existing (written) and, thus, analyzable form of the literary Mongolian language.

Results. It has been chosen as a source of linguistic material because the conclusions regarding the forming processes of household vocabulary would have thus a solid basis. The paper describes the following lexical items: büleü/büleür 'churning staff, a wooden stick with two cross-pieces or a disk on one end for beating kumiss', aur 'mortar; vessel in which substances are pounded or rubbed', kituqay 'knife', süke 'axe', šiüci 'chisel', šibüge 'awl', tebene 'a large needle used for sewing leather and other stiff material', čalir 'iron bar for demolishing rocks, breaking ice, etc.; crowbar, wrecking bar', gölmi qubčiur 'large fishing net', gü:rege 'bellows', uqali 'adze', kirüe 'saw'. It has been revealed that most of the words listed belong to the common Mongolic household vocabulary, and the words tebene 'a large needle used for sewing leather and other stiff material' and gü:rege 'bellows' are related to their common Turkic equivalents.

Keywords: Mongolic languages, Khalkha, Buryat, Kalmyk, vocabulary, tools of trade, common Mongolic, common Turkic 